\title{
A FORMAÇÃO CONTÍNUA DE PROFESSORES - NOVAS TENDÊNCIAS E NOVOS CAMINHOS
}

\author{
Nadja Maria de Lima Costa \\ Pedagoga no Centro Federal de Educação Tecnológica do Rio Grande do Norte (CEFET- \\ RN); Mestre em Educação a Distância - nadja@cefetrn.br
}

Recebido em outubro/2004 e Aceito em dezembro/2004

\begin{abstract}
RESUMO
O presente trabalho consiste em um recorte dos estudos sobre formação e profissionalização docente, abordando as questões teóricas dos modelos de formação continuada de professores no que se refere às suas características, formas de desenvolvimento no cotidiano escolar e na vida desses profissionais, bem como discute as implicações e contribuições que determinadas práticas trazem para o atual contexto educacional. Demarca a existência de dois grandes modelos teóricos de formação e suas formas multifacetadas de existência, quais sejam, as denominadas por alguns autores, como estruturantes ou clássicas e o modelo construtivista ou interativo-reflexivo. Tem a preocupação de traçar as necessidades para a formação do professor reflexivo, mapeando as novas tendências na formação continuada de professores em contraponto com o modelo clássico, e ainda aponta alguns caminhos a se percorrer baseado nestas sistematizações. A partir desse referencial, discutem-se as atuais mudanças na formação continuada de professores, a quem caberá um importante papel nesta dinâmica e como poderá ser articulado um modelo de formação contínua que valorize o espaço escolar e o permanente exercício da ação-reflexão-ação como um elemento intrínseco à formação docente. É um ensaio que visa a contribuir com as novas perspectivas da formação continuada de docentes na busca de uma significativa atuação profissional.
\end{abstract}

Palavras chaves: Formação docente, novas tendências e professor reflexivo

\section{TEACHER" CONTINUOUS FORMATION - NEW TENDENCIES AND PATHS}

\begin{abstract}
This work presents a particular approach to studies about teachers' formation and training, discussing theoretical aspects of their continuous formation models, concerning their characteristics, developing forms at everyday school, as well as in these professionals' lives, also discussing implications and contributions that specific practices offer to the present educational context. It delimits the existence of two remarkable theoretical models of formation and their multi-faceted forms of existence - the first one is named structural or classic by some authors, while the second one is known as constructivist model, also referred as interactive-reflective. The work is also concerned about tracing the needs required to form reflective teachers. It is mainly committed to mapping out the new tendencies related to teachers' continuous formation, establishing a counterpoint with the classical model, pointing out some ways to go through supported by these systematizations. From this referential, we discuss the present changes on teachers' continuous formation, who will be able to play an important role on the process and how a continuous formation model can be articulated, in order to value the school space and the permanent exercise of the action-reflection-action as an innate element to teachers'
\end{abstract}


formation. This work is an essay that aims at contributing with the new perspectives of teachers' continuous formation, in search of a significant professional performance.

Key words: Teacher’s formation, new tendencies and reflective teacher. 


\section{A FORMAÇÃO CONTÍNUA DE PROFESSORES - NOVAS TENDÊNCIAS E NOVOS CAMINHOS}

A busca da qualidade de ensino na formação básica voltada para a construção da cidadania, para uma educação sedimentada no aprender a conhecer, aprender a fazer, aprender a conviver e aprender a ser e para as novas necessidades do conhecimento, exige necessariamente, repensar a formação inicial de professores, assim como requer um cuidado especial com a formação continuada desse profissional com um olhar crítico e criativo. Essa preocupação é relevante, tendo em vista o atual contexto de reformas educacionais, que visam a dar respostas à complexa sociedade contemporânea.

Este é um tema de particular atualidade em função da recente reforma implementada em todos os níveis da educação brasileira, Educação Infantil, Ensino Fundamental, Ensino Médio e hoje em discussão a do Ensino Superior.

Uma reforma que merece um domínio profundo por parte dos atores que de fato conduzem o processo ensino-aprendizagem. Pois, as mudanças implementadas são de cunho filosófico, metodológico e sociológico implica numa postura dialética frente ao conhecimento, compreensão de processos cognitivos e metacognitivos, domínio do conceito de competência e sua construção na escola, entre outras exigências.

As referidas mudanças educacionais se baseiam em princípios filosóficos inovadores e têm fundamentos epistemológicos da pedagogia crítica. Porém, ao mesmo tempo tem como pilar de sustentação um movimento político-social de clara hegemonia do projeto neoliberal (FRIGOTTO, 1996).

Na implantação de qualquer proposta pedagógica que tenha implicações em novas posturas frente ao conhecimento, conduzindo a uma renovação das práticas no processo ensino-aprendizagem, a formação continuada de professores assume um espaço de grande importância (PERRENOUD, 2000).

A formação continuada de docentes é um tema complexo e que pode ser abordado a partir de diferentes enfoques e dimensões. A história mostra a existência do modelo clássico no planejamento e na implementação de programas de formação, bem como o surgimento de novas tendências de educação continuada praticadas na área profissional da educação, como também em outros contextos profissionalizantes.

Será abordada uma discussão a respeito das características do modelo clássico e das novas tendências na formação continuada de professores, suas contribuições para a profissionalização docente, bem como as implicações na operacionalização das propostas coexistentes e ainda, aponta caminhos para atender às atuais necessidades na formação de professores.

\section{Modelos de educação continuada}

O modelo clássico de formação continuada para docentes traduz-se no que vem sendo feito historicamente nas iniciativas de renovação pedagógica. A ênfase é dada na atualização da formação recebida ou numa "reciclagem" que significa "refazer o ciclo". 
Candau (1999), utiliza o termo reciclagem diferentemente de outros interessados no assunto que discordam da expressão por atribuírem a palavra "reciclar" como um termo próprio do processo industrial e aplicado à reutilização de materiais recicláveis, não condizente com a atual discussão da formação docente. (PRADA,1997, p.88).

Na visão de Prada (1997), os termos empregados para nomear os programas de formação continuada de professores estão impregnados da concepção filosófica que orienta o processo, recebendo também influências da região, país e instituições envolvidas, entre outros fatores. O autor apresenta algumas das diferentes expressões que são mais utilizadas na denominação dos programas desta formação com o objetivo de ampliar essa compreensão:

Quadro 01 - Termos empregados para formação continuada de docentes.

\begin{tabular}{|c|c|}
\hline Capacitação & $\begin{array}{l}\text { Proporcionar determinada capacidade a ser adquirida pelos } \\
\text { professores, mediante um curso; concepção mecanicista que } \\
\text { considera os docentes incapacitados. }\end{array}$ \\
\hline Qualificação & $\begin{array}{l}\text { Não implica a ausência de capacidade, mas continua sendo } \\
\text { mecanicista, pois visa melhorar apenas algumas qualidades já } \\
\text { existentes. }\end{array}$ \\
\hline Aperfeiçoamento & $\begin{array}{l}\text { Implica tornar os professores perfeitos. Está associado à maioria } \\
\text { dos outros termos. }\end{array}$ \\
\hline Reciclagem & $\begin{array}{l}\text { Termo próprio de processos industriais e, usualmente, referente } \\
\text { à recuperação do lixo. }\end{array}$ \\
\hline Atualização & $\begin{array}{l}\text { Ação similar à do jornalismo; informar aos professores para } \\
\text { manter nas atualidades dos acontecimentos, recebe críticas } \\
\text { semelhantes à educação bancária. }\end{array}$ \\
\hline $\begin{array}{l}\text { Formação } \\
\text { Continuada }\end{array}$ & $\begin{array}{l}\text { Alcançar níveis mais elevados na educação formal ou } \\
\text { aprofundar como continuidade dos conhecimentos que os } \\
\text { professores já possuem. }\end{array}$ \\
\hline $\begin{array}{l}\text { Formação } \\
\text { Permanente }\end{array}$ & $\begin{array}{l}\text { Realizada constantemente, visa à formação geral da pessoa sem } \\
\text { se preocupar apenas com os níveis da educação formal. }\end{array}$ \\
\hline Especialização & É a realização de um curso superior sobre um tema específico. \\
\hline Aprofundamento & $\begin{array}{l}\text { Tornar mais profundo alguns dos conhecimentos que os } \\
\text { professores já têm. }\end{array}$ \\
\hline Treinamento & $\begin{array}{l}\text { Adquirir habilidades por repetição, utilizado para manipulação } \\
\text { de máquinas em processos industriais, no caso dos professores, } \\
\text { estes interagem com pessoas. }\end{array}$ \\
\hline Re-treinamento & Voltar a treinar o que já havia sido treinado. \\
\hline Aprimoramento & Melhorar a qualidade do conhecimento dos professores. \\
\hline Superação & $\begin{array}{l}\text { Subir a outros patamares ou níveis, por exemplo, de titulação } \\
\text { universitária ou pós-graduação. }\end{array}$ \\
\hline $\begin{array}{l}\text { Desenvolvimento } \\
\text { Profissional }\end{array}$ & $\begin{array}{l}\text { Cursos de curta duração que procuram a "eficiência” do } \\
\text { professor. }\end{array}$ \\
\hline Profissionalização & $\begin{array}{l}\text { Tornar profissional. Conseguir, para quem não tem, um título } \\
\text { ou diploma. }\end{array}$ \\
\hline Compensação & $\begin{array}{l}\text { Suprir algo que falta. Atividades que pretendem subsidiar } \\
\text { conhecimentos que faltaram na formação anterior. }\end{array}$ \\
\hline
\end{tabular}

Fonte: Prada (1997, p.88-9). 
No modelo clássico, caracterizado por vários estudiosos, o professor que já atua profissionalmente com sua formação inicial volta à universidade para renovar seus conhecimentos em programas de atualização, aperfeiçoamento, programas de pósgraduação de latu sensu e strictu sensu, ou ainda, participando de cursos, simpósios, congressos e encontros voltados para seu desenvolvimento profissional. Esses, promovidos pelas Secretarias de Educação, onde os docentes estão vinculados ou por outras entidades interessadas na área.

Nesse modelo, permeia uma perspectiva de privilégios aos espaços considerados tradicionalmente como locus da produção do conhecimento, os quais são: a universidade e os demais espaços vinculados a ela. Nessa perspectiva, considera-se que a universidade é o local em que circulam as informações mais recentes, as novas tendências e buscas nas mais diferentes áreas do conhecimento. Embora não se questione tanto essa realidade, existe um aspecto crítico nessa visão, qual seja, a desconsideração das escolas de Ensino Fundamental e Médio como produtoras de conhecimento e passa-se a considerá-las como espaços meramente destinados à prática, local onde se aplica conhecimentos científicos e se adquire experiência profissional.

As pesquisas na área têm confirmado que é esse modelo clássico, que vem sendo praticado nos sistemas educacionais para a formação continuada dos profissionais do magistério, tem sido o mais promovido e portanto, o mais aceito.

Candau (1999), destaca quatro modalidades em que se apresentam tais iniciativas numa perspectiva tradicional.

Sob a forma de convênios entre universidades e secretarias de educação, em que as universidades destinam vagas para formar professores em exercício do ensino fundamental e médio nos cursos de graduação e licenciatura.

A oferta de cursos de especialização através de convênios entre instituições universitárias e secretarias de educação, visando à melhoria da qualidade de ensino tem sido muito praticada. Esses cursos são realizados em regime normal presencial ou na modalidade a distância, lançando mão de diferentes estratégias como, correspondência, via fax, vídeos, computador, teleconferência , ou outras mídias. Atualmente, no Brasil, existe um grande interesse na realização de cursos à distância e várias universidades já estão começando a montar cursos de aperfeiçoamento de professores nesta modalidade, não só para a rede pública, como também para a rede privada de ensino.

Embora tais experiências não estejam restritas à área de educação, as possibilidades que as novas tecnologias apresentam podem ser muito bem exploradas em prol da formação continuada, rompendo propostas tradicionais, distâncias geográficas e temporais. Mesmo lançando-se mão dos recursos tecnológicos, tais experiências mantêm ainda, as características do modelo clássico de formação continuada.

Uma terceira modalidade de formação continuada, na perspectiva tradicional, são as ações promovidas por órgãos responsáveis pelas políticas educacionais como, Secretarias de Educação dos estados e municípios e/ou o próprio Ministério de Educação, ofertando cursos de caráter presencial ou a distância. 
Além dos cursos promovidos de natureza presencial, insere-se também nessa modalidade programas de formação continuada a distância como os veiculados pela TV Escola, que se constitui numa formação aberta a todas as escolas públicas que possuam antena parabólica, receptor, TV e vídeo. O programa é vinculado ao Ministério da Educação e coordenado em todos os Estados pelas respectivas Secretarias de Educação. Embora estas iniciativas possuam características do modelo clássico, apresentam condições de ser trabalhada numa perspectiva de práticas inovadoras, onde as escolas se assumam enquanto lugares de formação como um exemplo vivo desse aspecto da interface. (NÓVOA, 1991).

Como quarta modalidade surge mais recentemente, ação de apoio às escolas, em que se incluem componentes de formação continuada de professores em atividade. A partir de um slogan "adote uma escola”, universidades ou empresas "adotam” uma escola situada em suas proximidades e desenvolvem programas específicos de colaboração em diferentes aspectos, oferecendo bolsas de estudos, equipamentos e outras formas de colaboração. No caso das universidades, oferecem programas de aperfeiçoamento em serviço para os professores.

Estes são exemplos concretos de atividades que se constituem como modelo clássico de formação continuada de professores, mesmo que se utilizem estratégias renovadas e lancem mão das mais avançadas tecnologias de comunicação e informação na forma presencial ou a distância. São modalidades que não inovam na sua prática, apenas canalizam espaço e tempo para a formação nos moldes já consagrados.

Na visão de Demailly (1992), os modelos de formação continuada de professores, classificam-se em quatro estilos ou categorias, a saber:

A forma universitária, que tem como finalidade a transmissão dos saberes teóricos. Tem características semelhantes à dos profissionais liberais-clientes, por ter caráter voluntário e pela relação constituída entre formador-formando, os mestres são produtores do saber e o aluno funciona como receptor dos conhecimentos.

A forma escolar, onde estão organizados todos os cursos através de um poder legítimo, exigem escolaridade obrigatória e existe uma instância organizadora onde os formadores não são responsáveis pelo programa nem por decisões administrativas. Possuem um papel passivo em termos de planejamento.

A forma contratual se caracteriza pela negociação entre os diferentes parceiros. Estes estão ligados por uma relação de troca ou contratual do programa pretendido, modalidades materiais e ações pedagógicas da aprendizagem.

A forma interativo-reflexiva, bastante presente nas iniciativas de formação voltadas para a resolução de problemas reais. Nessa modalidade, está presente uma ajuda mútua entre formandos e uma ligação à situação de trabalho.

Dentro desta concepção, a autora toma uma posição e destaca significativa diferença entre as formas universitária e a interativo-reflexiva. A primeira parece ser mais eficiente no plano individual. A segunda, é mais eficiente nos planos individual e coletivo porque suscita menor resistência por parte dos formandos, permite o prazer da construção autônoma, trazendo respostas aos problemas vivenciados, aborda a prática de maneira global e permite a criação de novos saberes para a profissão. 
Outros autores também defendem a forma interativo-reflexiva como uma maneira organizada e produtiva no processo ensino-aprendizagem, conforme afirma Gimeno Sacristán (apud NOVÓA, 1991p.89). O ensino como atividade racional ou reflexiva, como um fazer em que se mede cada passo dado e cada opção é fruto de um processo de deliberação, é uma prática utópica a que se aspira.

Nóvoa (1991) apresenta uma síntese dos modelos já discutidos, resumindo-os a dois grandes grupos, nomeando-os de modelos estruturantes e modelos construtivistas.

Os modelos estruturantes são organizados previamente a partir da lógica de racionalidade científica e técnica e ainda aplicados a diversos tipos de professores. O autor inclui neste grupo as formas universitárias e escolares citadas por Demailly (1992a).

Os modelos construtivistas partem de uma reflexão contextualizada para a montagem dos dispositivos de formação continuada, visando a uma regulação permanente das práticas e do processo de trabalho.

Este é um modelo que pode suscitar verdadeiras mudanças na prática, pois parte das necessidades dos educadores e se constitui em uma aprendizagem significativa, visto que os estudos teóricos têm ressonância na realidade cotidiana e visam a resolver questões anteriormente identificadas pelos envolvidos.

Entretanto, as sistematizações de Demailly e Nóvoa devem servir aos educadores como modelos teóricos de análise e não como modelos práticos de intervenção. Pois os próprios teóricos reconhecem que esses modelos não existem de maneira isolada na prática de formação de professores. Para Nóvoa (1991, p.20), “as estratégias de formação continuada são necessariamente híbridas, apelando segundo uma coerência própria e contextualizada a diferentes contributos teóricos metodológicos”. Nesse sentido, confirma Demailly (1992), a inexistência de "formas no estado puro".

É de suma importância o conhecimento desses diferentes modelos, a compreensão de que eles se materializam na prática da formação docente de maneira mista e criam novas formas e representações nessa complexa teia de atuações rumo à melhoria da profissionalização docente. Porém, a experiência tem mostrado bons resultados na metodologia ativa, construtivista e que proporcione ação-reflexão-ação.

Nesse contexto, não importa muito a forma em que se dão os programas de educação continuada. O que prevalece é a concepção filosófica entre teoria e prática, a compreensão do papel da universidade e das escolas de educação básica no processo de produção de conhecimento e qual o sentimento do profissional da educação e o sentido das instituições formadoras, enquanto agente de socialização de conhecimentos, voltadas para a melhoria do processo ensino-aprendizagem e da profissionalização docente.

\section{Novas tendências e recursos para um novo caminhar}

Em contrapartida à concepção clássica, atualmente vem se desenvolvendo reflexões, anseios e pesquisas científicas, visando à construção de uma nova concepção e práticas condizentes com as relevantes necessidades da formação continuada dos educadores. Esses caminhos estão delineando-se como novas tendências para a formação continuada de 
professores. É importante destacar que mesmo existindo modelos distintos como o clássico e as novas tendências, nenhum deles existe isoladamente em seu estado puro, sempre apresentam interfaces entre eles. Entretanto, é a partir da perspectiva predominante que se identifica em que modelo e tendência determinada formação está inserida.

As investigações recentes, e que estão conquistando consenso entre profissionais da educação, tratam de uma formação voltada para o professor reflexivo e tem como eixo central a própria escola. Desse modo, desloca-se o eixo da formação de professores da universidade para o cotidiano da escola de educação básica. Entretanto, ressalta-se que esse deslocamento é defendido em termos metodológicos, não que se queira depreciar a grande contribuição da universidade na formação docente.

Tal perspectiva rompe com a concepção clássica de formação continuada muitas vezes concebida como um meio de acumulação de cursos, conhecimentos ou técnicas. É entendida como um trabalho reflexivo da prática docente, como uma forma de reconstrução permanente de uma identidade pessoal e profissional em interação mútua com a cultura escolar, com sujeitos do processo e com os conhecimentos acumulados sobre a área da educação.

Para Nóvoa (1998), todo processo de formação deve ter como referencial o saber docente, o reconhecimento e valorização desse saber. Não é interessante se desenvolver formação continuada sem levar em consideração as etapas de desenvolvimento profissional do docente, ou seja, seus aspectos psicossociais. Existem grandes diferenças de anseios e necessidades entre o docente em fase inicial, o que já adquiriu uma considerável experiência pedagógica e o que já se encaminha para a aposentadoria.

Por esta razão, as novas tendências de formação continuada consideram estas diferenças e apontam sérias críticas a situações padronizadas e homogêneas, as quais são amplamente conhecidas como "pacotes de formação" que ignoram tais diferenças e não consideram o contexto no qual o docente está inserido.

Alguns pesquisadores sobre a formação continuada de professores revelam que, nessas tendências inovadoras, destacam-se três eixos que norteiam a prática docente e buscam adequá-las aos desafios do momento. Candau (1999), sintetiza esses eixos como pontos centrais de referências para se repensar a formação de professores adequada aos desafios do atual contexto. São eles:

- $\quad$ a escola deve ser vista como locus de formação continuada;

- $\quad$ a valorização dos saberes da experiência docente;

- $\quad$ a consideração do ciclo de vida dos docentes

Primeiramente, a partir dos estudos de Antonio Nóvoa (1991), a escola é vista como locus de formação continuada do educador. É o lugar onde se evidenciam os saberes e a experiência dos professores. É nesse cotidiano que o profissional da educação aprende, desaprende, estrutura novos aprendizados, realiza descobertas e sistematiza novas posturas na sua "práxis". Eis uma relação dialética entre desempenho profissional e aprimoramento da sua formação. 
Entretanto, essa perspectiva não é simples nem ocorre espontaneamente. Não basta acreditar que o cotidiano escolar favorece elementos para essa formação e a partir do seu trabalho, o professor está se formando continuamente. Nesse sentido, o pesquisador alerta:

"A formação continuada deve estar articulada com desempenho profissional dos professores, tomando as escolas como lugares de referência. Trata-se de um objetivo que só adquire credibilidade se os programas de formação se estruturarem em torno de problemas e de projetos de ação e não em torno de conteúdos acadêmicos”. (NÓVOA, 1991, p.30).

A fim de que o cotidiano escolar se torne um espaço significativo de formação profissional é importante que a prática pedagógica seja reflexiva no sentido de identificar problemas e resolvê-los e acima de tudo, seja uma prática coletiva, construída por grupos de professores ou por todo corpo docente de determinada escola. Sendo assim, tem-se uma rica construção de conhecimento em que todos se sentem responsáveis por ela.

Nóvoa (1991) destaca também a necessidade de se criar novas condições para o desencadeamento desse ousado processo, em que a escola seja explorada em todas suas dimensões formativas.

Para a escola se constituir enquanto locus de formação continuada, se faz necessária a promoção de experiências internas de formação, que esta iniciativa se articule com o cotidiano escolar e não desloque o professor para outros espaços formadores.

Essa compreensão implica na necessidade das instituições escolares criarem espaços e tempos institucionalizados que favoreçam processos coletivos de reflexão e intervenção na prática pedagógica através de reuniões pedagógicas, dentro da carga horária dos profissionais, construção coletiva do projeto político-pedagógico da escola, inclusive programa de formação contínua e avaliação coletiva deste. Cabe, também, criar uma forma de incentivo à sistematização de práticas pedagógicas a partir da metodologia de pesquisaação.

Outro aspecto relevante dessa compreensão é a mudança de foco da atuação pedagógica nas instituições escolares. Tal mudança implica numa nova concepção do trabalho do pedagogo nas escolas. Isso somente será possível se estiver muito claro qual é o papel desse profissional no atual contexto escolar. E qual o seu compromisso com a formação contínua dos docentes desenvolvida na própria escola. Numa visão crítica, Kramer (1989), apresenta dois eixos em que devem ser sedimentados o trabalho do orientador pedagógico ou supervisor em uma escola preocupada com a produção coletiva e com a qualidade do processo de formação continuada , quais sejam:

“Organizar a 'formação em serviço' em torno de temas ou problemas detectados como relevantes ou diretamente sugeridos pelos professores. Favorecer o acesso dos professores aos conhecimentos científicos em jogo nos diferentes temas, ultrapassando o senso comum: a) teorias que analisam o processo educativo de forma ampla (sociologia, antropologia, história, filosofia); b) estudos relacionados ao processo de construção do conhecimento (psicologia do desenvolvimento); c) conhecimentos que tratam diretamente o tema em questão”. (KRAMER, 1989, p.203).

No atual contexto educacional estão postos novos desafios para o profissional da pedagogia no cotidiano escolar. Esse novo fazer ultrapassa os aspectos burocráticos de exigências de planos de aula, de objetivos e avaliação, freqüência e notas, os quais 
necessitam de uma sistematização e de um olhar pedagógico, porém tais pontos não podem consumir o fazer do pedagogo/a na dinâmica do processo. Isto se resumiria ao puro tarefismo, deixando exposta a lacuna do profissional que conduziria a escola ao espírito inovador e de pesquisa baseado na ação - reflexão - ação. (Mendonça, 1991).

Nessa perspectiva dinamizadora das atuais tendências de formação continuada de professores, em que a escola é compreendida como lugar de formação continuada, orientadores pedagógicos ou supervisores e professores necessitam discutir a prática pedagógica, situada num contexto mais amplo e buscar as necessárias soluções.

Conforme Mediano (1992, p.32), esse trabalho parte de dois princípios: 1) converter as próprias experiências em situações de aprendizagem e 2) fazer uma reflexão crítica da própria prática pedagógica.

Entretanto, para que a escola redirecione sua prática de formação e redimensione o trabalho do pedagogo, é imprescindível que os dirigentes de escolas e os órgãos gestores da educação em conjunto com essa categoria, revejam os aspectos de atuação desse profissional no cotidiano escolar, contribuam para modificar a representação negativa que foi construída nesta profissão ao longo da história, desde a própria universidade e passem a compreender que este profissional não é um mero assistente ou acessório pertencente ao quadro administrativo da escola.

Nesse sentido, outro fator importante, destaca Mediano (2000), e a necessidade de os orientadores pedagógicos se desvincularem da insegurança que assola esse profissional em seu novo campo de atuação, ou seja, na formação de professores em serviço. Para vencer esse desafio, é importante a troca de experiências e a necessidade de se criar instâncias de trocas e de trabalhos coletivos, bem como se instalar um clima de confiança entre os pares.

Tardif (1991) destaca o segundo eixo das atuais tendências de formação continuada, como sendo a valorização do saber docente. O trabalho desenvolvido parte da investigação dos saberes dos professores, sua natureza, sua origem, na capacidade de construção e reconstrução de saberes específicos dos professores e das relações que estes profissionais estabelecem entre os saberes construídos no cotidiano escolar e as ciências da educação.

Os saberes da experiência são de extrema importância na profissão docente, se originam no trabalho cotidiano e no conhecimento do seu meio. São incorporados à vivência individual e coletiva e se traduzem em habilidades de saber fazer e saber ser. São conhecimentos que surgem da experiência e são por ela validados. É importante destacar que é através desses conhecimentos experienciados que os professores julgam a formação individual, atribuem valores aos planos e reformas implementados e definem determinados modelos de excelência profissional. Podemos compreender da seguinte forma: "eles constituem, hoje, a cultura docente em ação é muito importante que sejamos capazes de perceber essa cultura docente em ação, que não pode ser reduzida ao saber cognitivo”. (CANDAU, 2000, p.60).

É de extrema importância ressaltar a práxis reflexiva na cultura da formação, visto que os saberes adquiridos na experiência ficam relevados ao "ostracismo" e não são canalizados e sistematizados para um saber acadêmico. A própria Universidade não tem essa vivência, em seus cursos de formação inicial ou continuada para docentes, parte do zero e desconsidera um saber construído na experiência que necessita ser confrontado com a produção acadêmica. 
Para ratificar essa compreensão Nóvoa afirma: “A formação continuada deve alicerçar-se numa reflexão na prática e sobre a prática”, através de dinâmicas de investigação-ação e de investigação-formação, valorizando os saberes de que os professores são portadores. (NÓVOA, 1991, p.30).

Essa linha de pesquisa se constitui em uma importante iniciativa de reflexão no âmbito educacional. É um espaço de pesquisa emergente e pouco explorado, ainda tem muito a contribuir com o saber sistematizado da prática docente.

O terceiro eixo orientador das atuais tendências da formação continuada de professores centra-se na consideração do ciclo de vida dos docentes trabalhados por Hubermann (1992). É uma visão abrangente e unitária que possui grandes contribuições para a superação da dicotomia teoria - prática presente no modelo clássico

Essa é uma temática recente no meio acadêmico, vem abrindo uma interessante linha de pesquisa que visa aproximar as etapas do ciclo profissional de professores, conhecida na psicologia como ciclo de vida do adulto.

As contribuições de Hubermann, professor da Faculdade de Psicologia e de Ciências da Educação da Universidade de Genebra têm sido significativas para aprofundar o sentido da docência enquanto "carreira” profissional. Para o pesquisador esse conceito apresenta algumas vantagens:

"Em primeiro lugar, permite comparar pessoas no exercício de diferentes profissões. Depois, é mais focalizado que o estudo de "vida" de uma série de indivíduos. Por outro lado, e isso é importante, comporta uma abordagem ao mesmo tempo psicológica e sociológica. Trata-se, com efeito, de estudar o percurso de uma pessoa em uma organização (ou numa série de organizações) e de compreender como as características dessa pessoa exercem influência sobre a organização e são, ao mesmo tempo, influenciadas por ela”. (HUBERMANN, 1992 p.38).

Hubermann (1992) correlaciona os estudos clássicos do ciclo da vida individual trazidos da Psicologia com os estudos de um grupo específico de professores. O autor identifica estágios durante a carreira docente; passeia pela subjetividade do professor procurando conhecer a imagem que as pessoas têm de si como professores ativos, em diferentes momentos de sua carreira; o nível de competência com o decorrer dos anos, bem como procura estabelecer o diferencial entre os professores que chegam ao fim da carreira com sofrimentos e aqueles que a finalizam com tranqüilidade.

Em seus estudos, o autor identifica cinco etapas básicas que não são estáticas nem lineares, a saber: a entrada na carreira, tempo de sobrevivência e descobertas; a fase de estabilização, etapa de identificação profissional; a fase de diversificação, momento de buscas plurais e experimentações; a etapa de distância afetiva, lugar de serenidade e lamentação; e, finalmente, o momento de desinvestimento, próprio do final de carreira profissional.

Diante dessas considerações, é possível compreender que o ciclo da vida profissional é deveras complexo, o qual sofre interferências de múltiplas variáveis, muito embora, no desempenho da profissão muitas vezes, não são consideradas as mutações e os estágios psicossociais do educador. 
Contribuições dessa natureza são de grande valia para a discussão e prática da formação continuada, visto que é imprescindível à compreensão da heterogeneidade desse processo. É importante a tomada de consciência que as necessidades, os problemas, as buscas dos professores não são as mesmas nos variados momentos de sua profissão. Essa compreensão impede a realização de programas de formação que padronizem os profissionais em um mesmo lugar comum ou que desconsidere seus interesses e necessidades.

Nesse sentido, podemos refletir a respeito do ciclo de vida dos educadores articulado às novas tendências de formação centrada numa visão construtivista:

"É urgente devolver a experiência ao lugar que merece na aprendizagem dos conhecimentos necessários à existência (pessoal, social e profissional), na certeza que este processo passa pela constatação que o sujeito constrói o seu saber ativamente ao longo de seu percurso de vida. Ninguém se contenta em receber o saber como se ele fosse trazido do exterior pelos que detém os seus segredos formais”. (DOMINICÉ, 1990 p. 66).

Todas essas contribuições teóricas que concebem a escola como lócus de formação continuada, valorizam os saberes docentes e reconhecem que os ciclos de vida profissional dos professores se constituem como pilares para a fomentação das novas tendências na formação docente. Os conceitos e formulações tratados aqui visam à formação do educador reflexivo que tem como prática recorrente a ação-reflexão-ação enquanto elemento fundamental para se trilhar novos caminhos rumo à consolidação de um modelo construtivista de formação profissional do educador.

\section{REFERÊNCIAS BIBLIOGRÁFICAS}

BRASIL, Conselho Nacional de Educação. Parecer 15/98, de 01 de junho de 1998. Estabelece diretrizes nacionais para o Ensino Médio. Relatora: Guiomar Namo de Melo. Documento/Brasília, junho de 1998.

CANDAU, Vera Maria (org.).Magistério: construção cotidiana. Petrópolis: Vozes,3a Edição,1999.

CANDAU, Vera Maria e LELIS, Isabel Alice. A relação teoria-prática na formação do educador. In: CANDAU, Vera Maria (org.). Rumo a uma nova didática. Petrópolis, RJ: Vozes, $3^{a}$ edição, 1990, 49-63.

COSTA, Vera Lúcia Cabral (org.). Novas formas de coordenação e financiamento. (6998). São Paulo. FUNDAP.: Cortez, 1999.

DELORS, Jaques. Educação: um tesouro a descobrir - Relatório para a UNESCO da Comissão Internacional sobre educação para o século XXI. São Paulo: Cortez, 2003.

DEMAILLY, Lise C. Modelos de formação contínua e estratégias de mudança. In: NÓVOA, Antonio (org.). Professores e sua formação. Lisboa, Dom Quixote, 1992.

FREIRE, Paulo e FAUNDEZ, Antônio. Por uma pedagogia da pergunta. Rio de Janeiro. RJ: Paz e terra, 1985.

FRIGOTTO, Gaudëncio. Educação e a crise do capitalismo real. São Paulo: Cortez,1996.

GIL, Antonio Carlos. Métodos e técnicas de pesquisa social. São Paulo: Atlas, 1995.

GIMENO SACRISTÁN, J. Consciência e ação sobre a prática como libertação profissional dos professores, in NÓVOA, Antonio (org.). Profissão Professor. Portugal: Porto Editora, 1991. 
HUBERMAN, M. La vie do enseignants: evolution et bilan de une profession. Paris: Delachaux et Niestlé, 1989.

MEDIANO, Zélia D. A formação em serviço do professor a partir da pesquisa e da prática pedagógica. Rio de Janeiro. Tecnologia Educacional. No 105/106, 1992, 31-36.

MENDONÇA, Ana Waleska PC. A escola como espaço de formação continuada do professor. Brasília, DF: Revista de educação da AFC, n 79, 1991 p. 39-42.

MYNAIO, Maria Cecília de Souza (org.). Pesquisa social - teoria, método e criatividade. Petrópolis: Vozes, 1995.

NOGUEIRA, Adriano (org.). Ciência para quem? Formação científica para quê? A formação do professor conforme desafios regionais. Petrópolis: Vozes, 2000.

NÓVOA, Antonio (org.). Vida de professores. Portugal: Porto Editora, 1992.

NÓVOA, Antonio. Os professores e a sua formação. Tradução de Graça Cunha, Cândida Hespanha e Conceição Afonso. Lisboa: Dom Quixote, 1992.

NÓVOA, Antônio. Concepções e práticas da formação contínua de professores: In: Nóvoa A. (org.). Formação contínua de professores: realidade e perspectivas. Portugal: Universidade de Aveiro, 1991.

OLIVEIRA, Rosa M. Falando de criatividade. In: Formação contínua de professores: realidades e perspectivas. Portugal: Universidade de Aveiro, 1991.

PERRENOUD, Philippe. Pedagogia diferenciada: das intenções à ação. Porto Alegre: Artmed, 2000.

PRADA, Luis Eduardo Alvarada. Formação participativa de docentes em serviço. Taubaté. Cabral Editora Universitária, 1997.

SCHÔN, Donald A. In: NÓVOA, Antonio. Os professores e a sua formação. Lisboa: Dom Quixote, 1992.

TARDE, M.; LESSAD C. e LAHAY, L. Os professores face ao saber: esboço de uma problemática do saber docente. Teoria e Educação, no 4, 1991.

TAVARES, José e outros. Dimensão do desenvolvimento pessoal e social na formação contínua de professores. In: Formação contínua de professores: realidades e perspectivas. Portugal: Universidade de Aveiro, 1991.

TRAVASSOS, José. Dimensão pedagógica e didática na formação contínua de professores. In: Formação contínua de professores: realidades e perspectivas. Portugal: Universidade de Aveiro, 1991. 